\title{
Werr, Naoka (2019). Peruanische Bibliotheken als Bausteine der demokratischen Bildungspolitik [la ignorancia es la columna más firme del despotismo]. En R. Musser y N. Werr (Eds.), Das Bibliothekswesen in der Romania (pp. 307-316). Berlín: De Gruyter Saur.
}

Por la larga tradición historiográfica europea, el material publicado se constituye como una guía preliminar sobre las posibilidades de acercamiento a fuentes a través de la historia, gestión y servicios de los centros de información. El conocimiento sobre el acervo documental bibliográfico de los países estudiados permite análisis más profundos respecto a las relaciones culturales entre Europa y América Latina.

El libro constituye un primer acercamiento general a la diversidad de bibliotecas en los países de lenguas romances. Es conveniente para investigadores interesados en el desarrollo histórico y en la situación actual de sus bibliotecas, así como para los especialistas en filología románica. La primera parte del libro corresponde a los repositorios en Francia, Italia, España, Portugal y Rumania; las siguientes, a las antiguas colonias, por lo que se encuentran capítulos dedicados a Senegal, Malí, Camerún, Congo (África francófona), Angola, Guinea-Bissau, Cabo Verde, Mozambique, Santo Tomé y Príncipe (África lusófona), además de a América Latina (Argentina, Bolivia, Brasil, Chile, Ecuador, Colombia, México, Paraguay, Perú, Uruguay) y el Caribe (República Dominicana, Haití, Cuba, Puerto Rico). Son textos monográficos basados, en su mayoría, en información disponible en Internet.

El capítulo dedicado a Perú es el noveno de la tercera parte del libro. Inicia con la recopilación de datos por tipos de bibliotecas: del Instituto Nacional de Estadística e Informática (INEI), de la Asamblea Nacional de Rectores (ANR) y de la Comisión Nacional de Funcionamiento de Universidades (CONAFU). La siguiente sección profundiza en la historia de la Biblioteca Nacional del Perú, no solo desde su fundación, sino que menciona también a la biblioteca de la que heredó su colección: la jesuita del Colegio Máximo de San Pablo (fundada en 1568). Se detallan, igualmente, las funciones, colecciones y servicios de los locales de San Borja y Centro de Lima. Se describe también al Sistema Nacional de Bibliotecas a partir de su sustento legal y al Registro Nacional de Bibliotecas. 
Las bibliotecas públicas, así como las escolares, constituyen la última sección y su información está basada también en la normativa correspondiente.

Si bien todos los enlaces de la bibliografía consultada fueron revisados en diciembre de 2018, la inclusión de instituciones que ya no existían para ese momento (ANR, ahora Superintendencia Nacional de Educación Superior Universitaria-SUNEDU; CONAFU, ahora Sistema Nacional de Evaluación, Acreditación y Certificación de la Calidad Educativa-SINEACE), así como la carencia de un contraste entre la normativa nacional que sustenta a bibliotecas públicas y nuestra realidad, el texto no deja de ser punto de partida para nuevas investigaciones, actualizaciones y para la discusión sobre el límite de la información disponible. Ello sobre todo concerniente a la Biblioteca Nacional y al Sistema Nacional de Bibliotecas, al igual que para la formulación de normativa aplicable no solo respecto a los repositorios públicos, sino en especial sobre la situación de las bibliotecas escolares. El subtítulo del capítulo, frase de San Martín del Acta fundacional de la Biblioteca Nacional, nos recuerda también la posición actual de las bibliotecas en las políticas culturales y educativas.

La autora del capítulo dedicado al Perú y editora del libro, Naoka Werr, es doctora en Filología románica y ha trabajado en bibliotecas desde el año 2003. Actualmente es miembro de la Comisión de Información y Biblioteconomía, Educación y Cursos (KIBA) y del Comité de capacitación y examen vocacional de la Universidad de Ciencias Aplicadas de Baviera, donde es jefa del departamento de la especialidad de Archivos y Bibliotecología.

\section{Vanesa Becerra Málaga}

Universidad Nacional Mayor de San Marcos, Lima, Perú

Contacto: vanesabm@gmail.com

https://orcid.org/0000-0002-4625-7181 